Journal of Social Sciences 8 (1): 16-21, 2012

ISSN 1549-3652

(C) 2012 Science Publications

\title{
The Organization Culture: The Network Construction and the Ethical Development the Revenue Department, the Ministry of Finance
}

\author{
Yaowarin Srichainant, Songkoon Chantachon and Marisa Koseyayothin \\ The Research Institute of North Eastern Arts and Culture, \\ Mahasarakham University, Maha Sarakham, 44000, Thailand
}

\begin{abstract}
Problem statement: The organization culture should be organized in the form of network as a means of giving contribution to the organization office members. This study aims to investigate (1) The historical background of the organization culture of the revenue department (2) The present condition of the network formation of the etiquette-based organization culture development and (3) The network formation and the etiquette-based development of the revenue department, the ministry of Finance. Approach: The research area was focally conducted in the certain area of Bangkok Metropolitan. The population used included 98 subjects. The instrument used for data gathering consisted of the interview forms, the observation form, the focus group discussions and the participatory workshops. The obtained data were then discretely discriminated into classified group. The data were also examined by means of the triangulation technique which was then discreetly analyzed in accordance with the previously set purposes. To be concise, the analytical results were further presented in descriptive analysis. Results: (1) On account of the historical background of the organization culture of the revenue department actually started from the early age, that was, in the reign of King Rama V. The early age was the time when the leaders entirely applied the leadership of the organization. They, thus, totally assumed ultimate responsibility and also paid much respect to the seniority authorities. The middle age was the time when the organization culture was regarded as the most outstanding performance in the aspects of assuming ultimate responsibility and paying respect to the seniors. However, the organization culture became increasingly reliant on technology especially for the data collection. The present age was the period of time when a greater extent of emphasis had shifted from human reliance to technological reliance and also in terms of providing services from conventionally ways of practices to becoming more professional. However, high value was conventionally placed on humanitarian and righteous values. (2) The present condition according to the findings, the present time has also been apparent that the organization personnel are becoming more responsible for the tasks entrusted by the authorities and they also submitted to the discipline imposed by their leaders. Best of all, they have now submitted to the discipline or regulations imposed by their superior authorities. With their senses of belonging and self-adjustment, they have tried to maintain such qualifications as honesty, integrity and loyally to their organization. In addition, they have tried by all means to build up and stake the organization's reputation and images. (3) The network formation and etiquette-based development. With their strong impulse of reforming their organization to attain prosperity and improvement, the solid achievement could be constituted through the following 6 aspects: the ultimate responsibility, punctuality, holding the possession of righteous values, humanity; the deep understanding the religious principles of teaching. And has an acute sense of the respective order of seniority. As a matter of fact, the organization personnel have been classified into three different groups: Group 1. Those who have been work enthusiasts; all they need is to be given only tacitly emotional support; Group 2. Also the work enthusiasts, but have got some indirect marginal impact of a poor circumstance; Group 3. Consists of inert workers; the sole solution is providing them with the process of etiquette-based personnel development. Conclusion/Recommendations: To conclude, this study's results and implications provided made it possible to be applied in the formation of the network with greater contribution to raising the level of organization culture. Which, could result in the proficiency of working in groups, the services
\end{abstract}

Corresponding Author: Yaowarin Srichainant, The Research Institute of North Eastern Arts and Culture, Mahasarakham University, Maha Sarakham, 44000 Thailand Tel: +66-43-721686 
provided for recipients could be considered as culturally reciprocal interaction which is fully consistent with current conditions.

Key words: Organization, culture network, construction, ethical development, revenue department, ministry of finance

\section{INTRODUCTION}

Network formation and the etiquette-based organization culture development have been the very powerful significant driving force facilitating the organization culture to achieve its established visions and missions; particularly, the large government sectors as in the revenue department. As seen from the ratio of tax collection in the fiscal year 2007; the total amount of taxes having been collected by the customs duties department of revenue accounted for $74 \%$ of the total income from taxes having been collected or having gained by the ministry of finance and accounted for $67 \%$ of the income totally earned by the government. Exactly for the fiscal year 2008; they planned the target amount of customs duties to be collected would not be less than 1.2 million by million baht. For the fiscal year 2009; they planned the target amount of customs duties to be collected would not be less than 1.3 million by million bath. Moreover, the revenue department would also be liable for giving suggestions and making use of the customs duties policies for managing to collect taxes to reach the targeted amount throughout and impartially as well as total effective. Also, they are liable to play their roles as the mechanism of economic and social development. They have to try by no means to urge the tax payers to pay taxes voluntarily. The revenue department has been agency where not less than 12 million tax payers have come to transact each year. They have set up the policy to provide convenient, heartfelt, rapid, transparent and impartial service for tax payers. In economic crisis if the organization has got a plan to develop the etiquette-based personnel it would be able to improve their responsibility for obligation in giving people services. This would, in return, raise the level of services with respect to convenience, rapidity, modernization and transparency which would contribute to minimizing to a large extent the budget expense on tax collection management and, by product, earning more income from effective tax collection entrusted by the government.

These are the reason why the researcher has been inspired to investigate on "the organization culture": network formation and etiquette development. The department of revenue, the ministry of finance aiming to get well-informed about the process from which the organization personnel's etiquette had existed. Then, the fact about that process would be implemented for network formation and for etiquette-based organization culture development. The ultimate goal was to obtain the government agency organization having the concrete etiquette-based organization which would be fully equipped with decent well-versed personnel who are adept at thinking, understanding, speaking and earning their happy living.

This is the reason why the revenue department was selected to be the target for doing research on "organization culture": Network formation and etiquette-based development, The revenue department, the ministry of finance since, the revenue department was a large government organization connected with 984 networks all over the consisted of 22,000 officials and employees. It was also the main organization under the ministry of finance obligated to carry out the liable mission of collecting taxes and duties in compliance with the revenue code and the relevant enforced laws.

\section{MATERIALS AND METHODS}

The area of study was in Bangkok Metropolitan Area. The research was conducted by means of qualitative research. The data were collected from the sample obtained by Specified Random Sampling which included 28 departments and workgroups; Three regions division; 16 specified areas the revenue department; 51 distributions the revenue department; the total number are 98 subjects. The instrument used for collecting data consisted of the interview forms, the observation, the focus group discussions and the participatory workers. The data were collected from the sample obtained by specified random sampling which accounted for 95 respondents who were the 15 well informed 50 operators and 30 general information providers. The data obtained were examined and analyzed dependently on their aims. Then, the results are presented by means of "descriptive analysis."

\section{RESULTS}

(1) The historical background of the organization culture of the revenue department has started since 1873 in the reign of Great King "Chula Chom-klao Chao-Yu-Hua" (King Rama V). Evidently, this reign could be divided into three main ages which were the 
early age was the time when the leader executed his leadership exerted established authoritative instructor of the apprentices given instruction with the approach employed was to adopting focus on the practical sessions of ethically-based organization culture entirely pragmatic the well-trained ones were supposed to essentially be the right personnel with experienced enterprising, entitled engendered certified backgrounds becoming outstandingly responsibility and also paid much respect to the senior authorities. The Middle Age was the time when the organization culture was regarded as the most outstanding performance in the aspects of responsibility. The emphasis has been put on the etiquette-based organization culture development. However, the organization culture became increasingly reliance on the information technology and communication. This age would rather be known by the name Electronic Revenue "e-Revenue". Since, 1997 up till the present time. The organization culture it has come to the based on etiquette values were so prominent. It was the age when eminent the increased emphasis was placed not only given bore to the professional service- giving providing for the public but also always providing vital services in mind the sense of common humanity, but all well the true value was rightly fostered. (2) As it was found, the present condition of the formulation of the network of etiquettebased organization culture development. As for the etiquette-based organization, most personnel have the ultimate responsibility for accomplishing the assignments entrusted by the senior authorities. They have to maintain such qualifications as having total honesty and faithfulness as well as integrity and remained loyal to the organization and, last but not least, trying by all means extremely to stake the organization's reputation and image. As for the etiquette for their senior, they were respect and be obedient and perform the tasks entrusted to the most perfection. The subordinators were obligated to pay respect to them and to perform the tasks entrusted, also to express critical ideas in case a performance constitutes a breach of etiquette or regulation and, worst of all, illegal actions. They were honesty, trustworthiness provided for their senior. As for their own etiquette, they have to maintain such qualifications as having total honesty, faithfulness, sincerity, truthfulness, hard-working and remaining loyal to the organization, working with the exertion of high knowledge and skills and with transparency. The etiquette for their staff workers, personnel keep working together cooperatively, mutual assistance, sincerity and work altogether in unity. The etiquette for taxpayers, the organization personnel have to keep up with the service-minded principle treating them impartially and with absolute justice, politeness, convenience, rapidity, efficiently and keep working on time. (3) With respect to network formation and etiquette-based development, the revenue department, the ministry of finance, the etiquette-based organization development. The six aspects of etiquette development included Responsibilities, Punctuality, having the rightful values, having humanity, thorough understanding of religious principles and awareness the basic tenets of Buddhism and has an acute sense of the respective order of seniority. The organization personnel were, thus, divided into 3 groups: The first group consists of work enthusiasts; all they needed was merely the slightest encouragement. The second group, also, the work enthusiasts but having got an impact by the environmental factors. The third group consists of inert personnel; Thus, this, group requires an extra process of etiquette-based development so that the problem could be alleviated.

\section{DISCUSSION}

Based on the study results the following discussions could be made: The historical background of the organization culture of the Revenue Department had begun in the reign of His Majesty, "King Chullachomklao Chao-Yu-Hua" (King Rama V) who had initiated the Reformation Plan of the government and royally granted the reorganization of the financial systems. His Majesty had established the hall of Evolutionary Revenue in 1873 in order that the customs and the duties of the Kingdom could be solely gathered at this Hall on the whole. Later, the Hall was royally granted to be elevated to become the royal ministry of finance. beside, His majesty graciously preferred the Kingdom to organize the budget allocation for the first time and that initiation had become an ideal model to be consecutively practiced annually. In conclusion, the early age, the possible inference was the initial age was the period of time when the heads or the leaders fully utilized their leadership. The instruction of apprenticeship had become teaching in obvious parallel with practiced training by doing the similar practice to the instructional guideline provided by the senior executives. The etiquette-based organization culture become extremely prominent paying respected to its great responsibility and best of all it has given mutual respectability. Of seniority. As it may seem they were really proud of themselves becoming members of the 
organization. The middle age was the age when the organization culture prominently placed responsibility and focused the etiquette-based organization culture on the aspect of academic values, particularly, in the field of information Technology. And communication or this age was properly called the "e-Revenue". Since 1997 the main consequences, in turn, were that the organization personnel themselves were encouraged to independently express the ideas out of the same old framed ones. They were also stimulated to start with their own wits and talents no matter how different these were from their superiors. The present age, the emphasis has been placed on the professional serviceproviding. The etiquette-based organization culture's outstanding point is to promote the sense of responsibilities, humanity and right values. Now, it has been developed into the present from witch has been adjusted to suit currently events contemporary. The Revenue Department was regarded as a unit of work in which the work performance policy has been in conformity to the ideas relevant to the absolute right and duties according to Rapport and Overing (2007) mentioned that the subsystem of the structure related to the economic activities. The economic unit is, thus, so important from level the family up to the whole empire. These two factors have rendered the mutual contribution to giving enough supportive to each other so that they could remain in subsistence the society.

The present condition of the etiquette-based organization culture network. On account of this certain aspect the researcher found that the revenue department was the government agency which have been revealed obligated to take responsibility for collecting taxes to such an extent of making a whole collecting while maintaining impartiality. It was the aspect of the condition of etiquette-based organization culture network formation the whole revenue department in the six aspects including: (1) the etiquette provided for the organization: the personnel performed their duties with basis of honesty, trustworthiness and with the full realization of their obligation which partly depends on the anxiety to gain more knowledge and acquisition. Owing to the fact that the revenue department has been obliged to perform their tasks on the basis of accuracy and legitimacy (2) With respect to the etiquette provided for their senior authorities, all the personnel have to show respect and obedient and perform the tasks entrusted to utmost completion. 3) With respected to the etiquette in their own selves, the personal are liable to perform their tasks proficiently, effectively with the intent of maintaining the virtue standard, together with, the maintenance of their own dignity and honor, discipline themselves in conformity with the decent customs. (4) With respect to the etiquette for their staff workers. Personnel working collaboratively as a team, they are supposed to perform the tasks with the intention of achieving the level of efficiency. They have to work altogether with great generosity with the consent to assisting in the work accomplishment. (5) In the aspect of etiquette for the subordinators. The censor authorities have to behave themselves as good leaders. (6) With respect to the etiquette for the tax payers, the organization personnel have to maintain the service minded principle by treating them impartially and with absolute justice infirmity to the Buddhist philosophical precepts. Which are relevant to finding solution to the problems by means of etiquette as described in the Dharma Pitaka the third level certificate in Pali Studies with Payutto (2006) has an opinion of how to solve the problems by the following 4 items: (1) Every problem can be solve, or found the best way out; or there is a way when there is a will. It doesn't matter how big the problem is. Thus, when there is a problem arising in the organization, it is essential that the combining strength will be organized into a network. (2) Find out that is cause of the problem. That is to say, the strategic solution to the problem with reference to the Four Noble Truths: which state that to solve a problem is to solve the cause. Briefly speaking, each organization has to be reunited as the combine strength.

The human being's problem should be solved by one's own. A good start will lead to the whole image problem-solving.4) Solve a problem direct to the point, concentrate on the initial cause and look into the problem in depth in order to get to its root then carry out the problem-solving; all being that as it may to join in one altogether between the authorities and subordinators must lie in the following practical advice: (1) Kindness, affection, best whishes for their happiness, generosity, amicability, beneficiary and common interest. (2) Compassion, sympathetic, being helpful suffering, pay attention to release the suffered from adversity and trouble of human and animals. (3) Sympathetic, congratulations on someone happiness. (4) Equanimity, be natural mind and consideration of justice.

There are some other findings in conformity to the study conducted by Durong-Detch (2006) on "The Investigation of organization culture versus the anticipating culture and efficient leader: A case study of Thai Oil Company Limited." Applying the "frame of thought" based the study on globe's guideline of study 
which consists of various factors, for instance: Form and Feature of exerting one's dictatorial power/authority; The features of keeping away from uncertainty; The feature of masculinity; The features of being individuals; The characteristics of emphasizing achievement; The characteristics of emphasizing humanity and the features of emphasizing the future.

The population used in the study consisted of the total of 54 middle-ranked administrators of the Thai-Oil Limited: The results of the research indicated that there was no significant relationship between the existing organization culture and the features of organization culture highly expected as being exceptional; with respect to the feature of being individual and the feature of masculinity having no significant relationship between the existing organization culture and the characteristics of efficient leaders. Except that the feature of avoiding from uncertainty and the characteristics of efficient leaders are most likely to be male, emphasizing both the future prospects and also the success.

The other conforming findings of the study conducted by Rangseenon (2008) on "The Perception of Organization Culture and the ties they have with the organization of employees in the hotel business in the Pattaya City Limits, Chon Buri Province. The groups of sample employed in the research consisted of 372 hotel service personnel who had been members of the Society of 10 Thai Hotels, Pattaya City Limits, Chon Buri Province. The subjects were obtained by Random Sampling by means of the Yamane's sample size calculation formula of which the first section of the these subjects were the hotel personnel who had got the perception of the organization culture. Based on Daft's ideas, the researcher had divided the organization culture into four different types as follows: The adjustable organization culture; the notable achievement springing organization culture; relative organization culture; and the officially hierarchical organization culture. The second part, on the other hand, had an obligation to the organization, the researcher formally adopted Allen and Mayor's ideas in which obligations had been distinguished into three aspects as follows: spiritual obligation; existent obligation; and norm obligation.

The results of this study revealed that by the overall view the hotel employees in Pattaya City, Chon Buri Province had perceived organization culture to a large extent in every aspect. However, the officially hierarchical perception had been ranked the first in priority. With respect to the obligation to the organization of the employees, the findings indicated that most employees had spiritual obligation to the organization; the existent obligation was of a considerable level, the norm obligation was of an average level.

The network formation and the etiquette-based development with relevance to the revenue department, the ministry of finance. On this account, the researcher could be based on the findings to reveal that the network formation and the etiquette-based development of organization culture. Also, the findings indicated that the organization development of the revenue department, the ministry of finance would be possible if the six aspects of morality had been developed as follows: responsibility, punctuality, having righteous values, humanity, thorough understanding of religious principles and awareness of seniority by means of breaking the organization personnel into groups, which were in parallel to the research conducted by Nimit (2005) on "conducting research and developing the process of virtue formation together with morality possession. The researcher put forward the Viewpoint, for instance, a perfect virtuous and moral person would be clearly characterized both for the benefit of oneself and also for others, including for the whole society to such an extent of communitywide acceptance and, as a result, becoming a decent model of the society. As a discrete item, it was found that a moral person would not only be characterized by the possession of morality, but particularly also with the focus on the development of virtue in themselves including as well having good merit with regularly practice of merit-making and, in practice, behave themselves in accordance with the code of morality by holding on the five Buddhist precepts and the four paths of accomplishment, etc. and, best of all, the formation of the good personal characteristic attributes for oneself in a conspicuous way and simultaneously, develop the virtue in relevance to others, such as, being responsible for one's own family, for instance, taking care of their children, providing other people with hospitality and generosity. Besides, some other decent characteristics are not to exploit, are not jealous, are not to gossip others but discipline himself to easily forgive others and also to be patient with annoyances from noisy environment. Besides, the morally qualified persons with virtue would be able to contribute a great deal to playing their role in joining the communities, societies and environment getting involved with by this research, for instance, the strong loyalty to the nation, the religion and their majesties. Other than these, they are obliged to have high regards to social regulations, legal restrictions and social norms. Since, people have been encouraged to boldly encounter all the public problems in common it is, therefore, it is essential to maintain the 
value of decent things. They have conscious awareness of public affairs to such a great extent that they could a good model for the society. These facts arrive at the conclusion that the morally qualified persons trigger to make a great positive virtues either at the level of family matter or the level of community concern.

\section{CONCLUSION}

This study could be applied to the network formation of etiquette-based organization culture developed by the researcher to try out with the personnel in active service of the Office of Information Technology where the researcher is now at work as an official. The researcher could positively affirm that my work performance under the principles applied in this study has been efficient and highly conducive to attaining the organization task achievement. If the results of this study were applied to such a concrete extent to the development of etiquette-based organization culture development, then they would contribute to a large extent solving the problems encountered by both the foremen and the subordinators. If the theoretical descriptions above could be entirely feasible, the personnel's responsibility and punctuality would actually come into existence, the forms of network formation resulted from the etiquette-based organization culture development proposed by this study seem to imply that the findings should be modified and transferred to many other sectors.

\section{REFERENCES}

Durong-Detch, S., 2006. The Evaluation of Bangkok Metropolitan City: The Enjoyably Magnificent Compound Appraised by the World Health Organization. Royal Acad. Perio.

Nimit, A.S., 2005. The form of enhancing the power of the sub-district administrative organization for the sake of community development: The humanities and social sciences periodical. Mahasarakham University.

Payutto, 2006. The Buddhist Dharma Scriptures: Sustainable Development. 1st Edn., The Foundation of Komon Keem Taung, Bangkok, pp: 2549.

Rangseenon, K.K., 2008. Strategies employed in the development of community economy: Community development periodical.

Rapport, N. and J. Overing, 2007. Social and Cultural Anthropology: The Key Concepts. 2nd Edn., Routledge, New York, ISBN-10: 0415367514, pp: 513. 